\title{
Starting a Student Satellite Program
}

\author{
Eric Wang, Jeffrey LaCombe, James Detweiler, and Daniel Loranz \\ University of Nevada, Reno/Truckee Meadows Community College
}

\begin{abstract}
The Nevada Space Grant Consortium's student satellite program, NevadaSat, is an ongoing multi-faceted program providing students with high-impact exposure to the aerospace fields. The program includes multidisciplinary student activities in scientific ballooning, rocketry, and Earth-orbiting satellites, known as BalloonSat, CanSat, and CubeSat, respectively. All of these programs are active and critical towards achieving the goal of producing a student satellite to be launched into Earth orbit in the next 3-5 years. Producing and flying a CubeSat is a complex and challenging endeavor. It necessitates support through "training" programs like BalloonSats and CanSats, which build the necessary hands-on skills in students and build interest.

This paper begins by presenting an overview of student satellite programs that exist both nationally and locally. Next the process of starting and supporting a multidisciplinary student satellite program is described and the results to date are presented. Finally, the benefits of the program and initial assessment results are discussed.
\end{abstract}

\section{Background on Student Satellites}

The National Space Grant Student Satellite Program was created to address NASA's future workforce development needs. NASA has a strong need for engineers, scientists, and managers who have experience working in interdisciplinary teams. Similarly, NASA is a leader in the use of remote operations in the form of telescience or telecontrol of robots because of the numerous spaceflight missions conducted each year.

The Nevada Space Grant Consortium's (NvSGC) student satellite program, NevadaSat, is one of the many programs within the National Student Satellite Program [1]. Students participating in NevadaSat are studying and developing complex systems that will lead to NvSGC's future goal of launching a student-built satellite into orbit. The approach taken uses a process of graduated steps in program complexity - the formula followed by other successful Space Grant Consortia such as Arizona State University, who use CanSat as a primer for students desiring to become involved in their larger-scale CubeSat program (both CanSat and CubeSat are described below).

According to the National Space Grant Student Satellite Program [1]:

Across America, Space Grant students are learning from the ground up-literally — by designing, building, flying and operating a broad range of spacecraft. Students come with an interest in Space, but with different levels of 
skill, knowledge, and experience. Missions of growing complexity provide opportunities to acquire baseline skills and then to build on them. We call this strategy "crawl", "walk", "run" and "fly!"

This craw, walk, run, and fly euphemism forms the core of the NevadaSat Program. Our roster of activities begins with BalloonSats (Figure 1, left), where students build payloads out of kits with data logging equipment, a timer, a camera, and material to build an enclosure. The payloads are attached to a lanyard, parachute and a weather balloon. The weather balloon provides lift for the students' project and sends them up to a predetermined height. The data logging equipment records data such as radiation, temperature, and pressure.

CanSats (Figure 1, center) represent the next level of complexity in the student satellite program. In this case, the student payloads fit inside a standard soda can (hence the name "CanSat") and are launched to an altitude of approximately 2 miles via a high power rocket. Attending the rocket launches is always the highlight of this activity.

CubeSat (Figure 1, right) started in 1999 as a collaborative effort between California Polytechnic State University San Luis Obispo, and Stanford University's Space Systems Development Laboratory. The purpose of the project was to provide a standard for the design of picosatellites so that a common deployer could be used. In this way costs and development time could be reduced, resulting in increased accessibility to space and frequent launches. Currently more than 30 high schools, colleges, and universities from around the world are developing CubeSats.
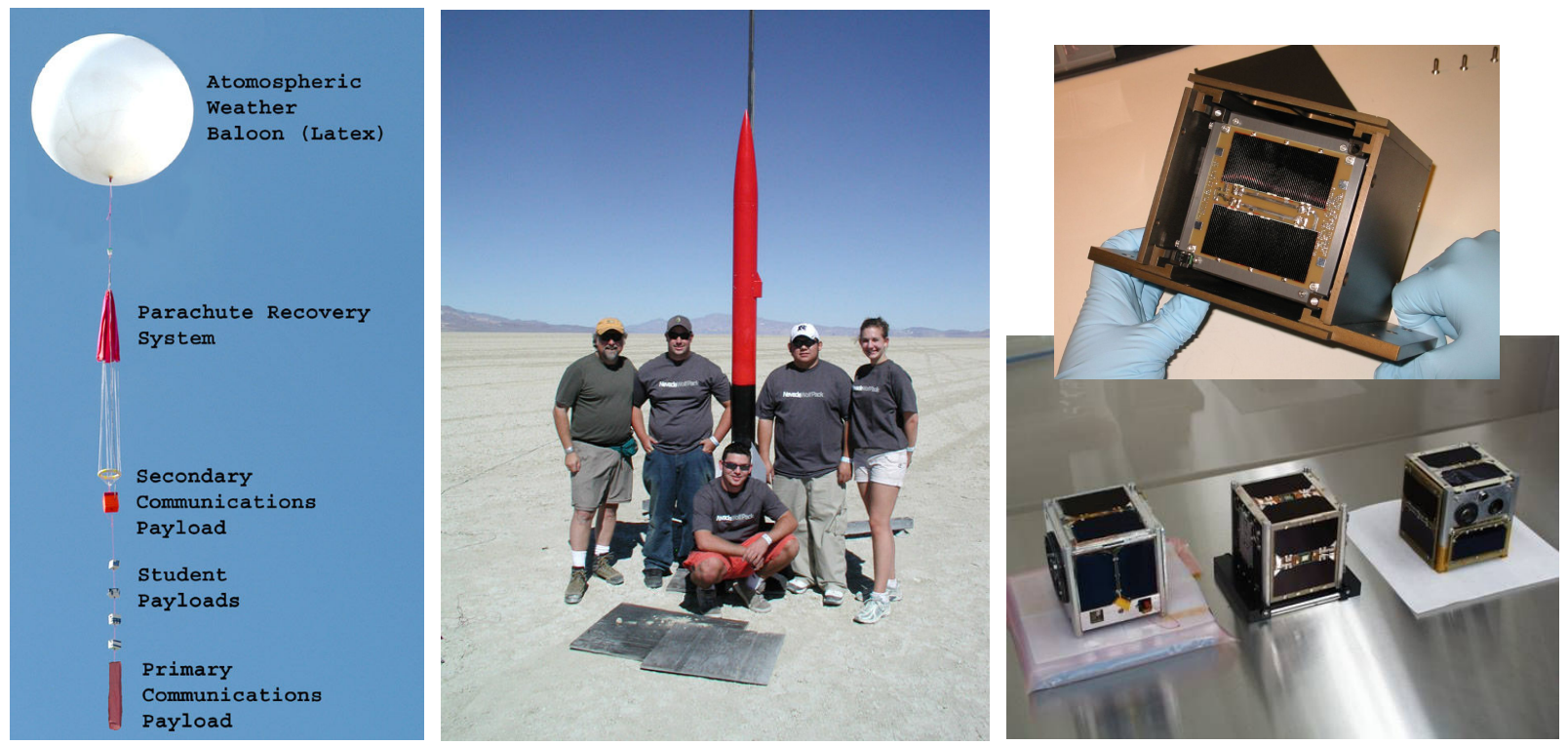

Figure 1: BalloonSat (left), CanSat (center), CubeSat (right) [Photos of CubeSats reproduced from courses.ece.uiuc.edu/cubesatpub/intranet/pictures.htm] 


\section{National and Local Student Satellite Programs}

\section{$\underline{2.1 \text { BalloonSat }}$}

As addressed in the previous section there are several stages associated with the student satellite program. The first, which is relatively undocumented, is the BalloonSat program. Only one article has been found on this subject [2]. There are, however, many publications regarding the use of NASA ballooning programs [e.g., 3-13]. These programs involve the use of balloons as low cost low orbit platforms. Several projects involve either developing less expensive or longer lasting high altitude balloons. Some of the articles point out the benefits of using balloons to carry payloads up to $30 \mathrm{~km}$ altitude for weather monitoring and other forms of data collection.

A fairly comprehensive list of other universities' BalloonSat programs can be found online [1]. The University of Arizona has compiled a list of all the universities involved in any aspect of the National Student Satellite Program. However, this list does not include any of the universities that have started a ballooning program after attending the 2002 workshop at the University of Colorado, Boulder, Starting Student Space Hardware Programs [14].

Ballooning is the easiest program to start as it has no real size constraints and a generous weight constraint of $6 \mathrm{~kg}$. Unlike other programs which might require high gain, highly directional antennas, balloons can be tracked using omni-directional antennas. Recovery is provided by amateur radio licensees (HAMs) monitoring the balloon's position with radios from cars. Most balloon flights contain simple experiments, which record changes undergone by the payload during its ascent and descent. However, BalloonSats are also used as low-cost testbeds for CubeSat hardware [2]. A typical BalloonSat configuration used by NevadaSat is illustrated in Figure 1 (left).

\subsection{CanSat}

CanSats derive their name based on the size and weight constraints of the satellite: all components must fit inside and have a mass no greater than a standard soda can $(350 \mathrm{ml}$ and $350 \mathrm{~g}$ respectively). CanSats are launched via amateur rockets to altitudes upwards of $4 \mathrm{~km}$. Figure 1 (center) shows several NevadaSat students preparing for a typical deployment.

To date, the two major CanSat competitions include A Rocket Launch for International Student Satellites (ARLISS) and the CanSat Competition [15, 16]. For the past few years, ARLISS has held an annual event at Nevada's Black Rock desert (Figure 1, center) where the objective is to have students complete a satellite development-launch-recovery lifecycle in a single year. ARLISS has several forms of participation, including a general CanSat program (noncompetitive) and an "Open Class" where schools compete against each other to build payloads that can find their own way back to the launch site (the distance traveled varies, but can exceed $15 \mathrm{~km})$.

The Annual CanSat Competition is new competition and includes all aspects of satellite development ranging from mission proposals all the way through payload recovery. Like ARLISS, the overall objective of the CanSat Competition is to provide students with a realistic low-cost experience in space systems. For 2005, there are two separate competitions: the 
undergraduate (rookie) mission for teams new to CanSats and the graduate (advanced) competition for teams with prior CanSat experience.

While dozens of websites can be found relating to various aspects of CanSats, only a few archival publications have been found concerning CanSat programs [17, 18].

\section{$\underline{2.3 \text { CubeSat }}$}

The ultimate goal of the National Student Satellite Program is envisioned to be a 52 spacecraft flotilla to Mars composed of student built spacecraft (one for each Space Grant consortium). It is hoped that all 52 will be able to travel at the same time, and that each will be able to provide useful information about Mars once the flotilla has arrived.

As a precursor to the Space Grant flotilla, students construct a CubeSat, which is a satellite that measures $10 \mathrm{~cm}$ on all sides (Figure 1, right). These are used as the ballast on commercial space flights, and are deployed for universities by a number of different countries. The CubeSat must have a $1 \mathrm{~kg}$ mass and they are quite expensive $(\$ 40,000)$ to launch. These typically require very high gain and computer controlled antennas on the ground to receive their transmissions.

The goal of all CubeSat programs is to help students develop the skills necessary to succeed in an aerospace workforce. These satellites perform tasks such as monitoring upper air pollution and testing the integration of new systems. CubeSat also provides a learning experience for students in ionosphere measurements and high tech imagery [1].

Many references can be found regarding CubeSats that cover topics ranging from guides to creating specific systems to methods for starting a CubeSat program [e.g., 19-30].

\section{Experiences with Starting a Student Satellite Program}

For the past three years the Nevada Space Grant Consortium has been developing the NevadaSat program, which currently encompasses the BalloonSat, CanSat, and CubeSat activities. From an institutional standpoint, the funds required to start a student satellite program are significant ( $>$ \$200k). Fortunately, the Nevada Space Grant Consortium and the National Space Grant College and Fellowship Program have made funds available through various workforce development projects. Additionally, a core group of enthusiastic faculty is also required to start a student satellite program.

The BalloonSat activities started after attending the StudentSat workshop at the University of Colorado, Boulder [14]. From the outset it was known that high altitude ballooning would be difficult in Nevada because the prevailing winds are West to East and the mountains tend to extend North to South (Nevada has more mountain ranges than any other state in the U.S.). This, coupled with the lack of roads (see Figure 2), caused much skepticism initially.

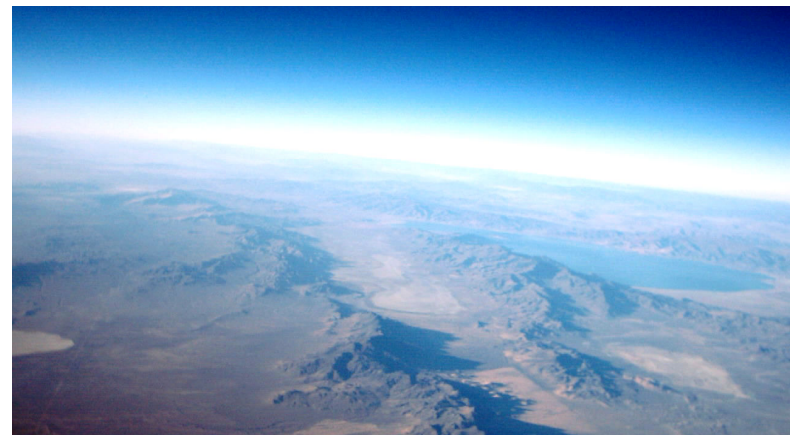

Figure 2. Student payload photo taken from 40,000 feet. The lack of easily accessible recovery zones can be seen. 
Confirming initial concerns, to date there have been six BalloonSat launches in Nevada, with the payload being recovered only four times. The initial failures indicated that starting a student satellite program in Nevada would be difficult. Clearly the "typical" BalloonSat methods used by other institutions would not suffice in Nevada.

To increase the likelihood of landing at the target recovery zone (which is small due to the geography), a telemetered cut-down system is employed. Based on the balloon trajectory, the payload can be cut loose from the balloon at any time during the mission.

Similar to other BalloonSat programs, NevadaSat uses a HAM radio and GPS as the primary tracking system (Figure 3 ). However, to increase the likelihood of payload recovery, a satellite-based tracking system is also employed as a backup tracking system. Unlike HAM radios, the satellite based system does not rely on line of sight for communication. Payload position data is sent directly to the ARGOS Earth orbiting satellite system and is available for download 2 hours later via the Internet.

While high altitude ballooning is traditionally touted as the easiest student satellite program to start, in Nevada it has proved quite difficult. Conversely, CanSats are traditionally considered a more advanced student satellite activity than BalloonSats but has turned out to be an easier program to start in many ways. While CanSats are more technically complex, the program is logistically easier to start because the ARLISS competition is held in Nevada each year (the Black Rock Desert is one of the premier launch sites in the world and is only 2 hours from Reno) [15]. Thus, for the past two years, NevadaSat has participated in the ARLISS competition with varying degrees of success.

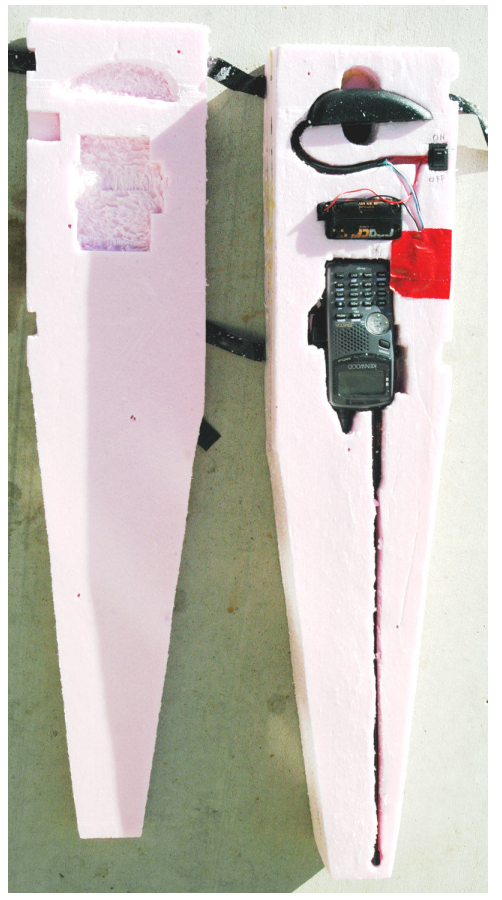

Figure 3. Typical tracking system consisting of a HAM radio and GPS.

The rockets used at ARLISS require special certifications and (in some cases) even require federal licensing to purchase and use. They typically reach altitudes in excess of 10,000 feet and speeds approaching Mach 1 (see Figure 1, center). The CanSat program uses such rockets but the students do not perform the actual rocket vehicle design and launching. Instead, the certified amateur rocketeers do the rocketry part, working closely with the student groups who make the payloads (i.e., the CanSats). This operational paradigm is analogous to the mode in which NASA operates with other commercial lift services to provide launch services to a customer who provides the payload.

As mentioned previously, the "Open Class" ARLISS competition involves developing a system which can autonomously bring back the CanSat to the launch site. Most competitors have attempted to develop either a guided descent vehicle or a small robot contained inside the CanSat that can drive itself back to the launch site. The NeavdaSat team has focused on the development of an autonomous rover than can locate the payload and return with it to the launch site. As a first step towards a fully autonomous rover, a remotely controlled rover (Figure 4) was 
developed that could be driven from a control center across the desert to pick up the payload and return it back to the launch site. The system worked well in nearly all respects, except for the transmission range of the video transmission system used for driving.

In addition to participating in "Open Class" ARLISS competition, NeavdaSat is also planning to participate in the general (noncompetitive) CanSat portion of ARLISS. NevadaSat has begun developing a student satellite workshop that focuses on CanSat. The experience gained thus far with "Open Class" CanSats, coupled with the proximity to the ARLISS event were large factors in the decision to develop a CanSat workshop.

Modeled after Colorado's BalloonSat workshop [14], the CanSat workshop will incorporate hands-on activities, including building, programming and launching CanSats. An expandable "CanSat Kit" was developed (Figure 5), consisting of a GPS sensor, temperature sensor, a HAM radio, and a micro-processor. In the summer of 2004, 12 complete CanSat kits were assembled and a pilot version of the workshop was offered to students from local secondary schools and colleges. Eight students participated, including attending a trip to the Black Rock Desert to launch and operate their CanSats. This workshop provided valuable feedback to further refine the activity.

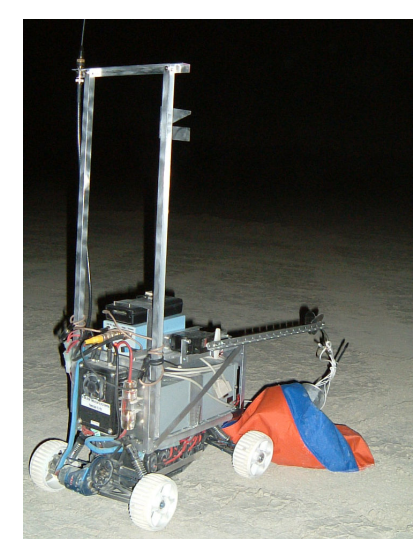

Figure 4. Rover used to retrieve the CanSat payload at the ARLISS competition.

Like most student satellite programs, NevadaSat has the long-term goal of launching a student built satellite. The BalloonSat and CanSat activities described thus far are viewed as workforce development programs for the CubeSat program. In 2004 the CubeSat program formally began in Nevada. The first activity was to participate in the $1^{\text {st }}$ Annual Cubesat conference, where the team had an opportunity to familiarize themselves with the community of other programs and their status. At this conference, much advice was received on how to start a CubeSat program. As a result, the NevadaSat team immediately began planning a ground-based satellite communications station, which will be tested using both BalloonSats and CanSats.

In addition to the various project activities, the development of an engineering course dealing specifically with student satellites was viewed as a critical task. To this end, a curriculum for a new interdisciplinary Student Satellite course to support NevadaSat activities has been developed. The course will be offered for the first time in the spring of 2005. During the past year, the instructors developed the curriculum concept where students participate as members of teams, working in a project-based learning environment on separate (but related) activities in aerospace systems engineering. Skills-based lectures will be provided throughout the semester. Teams will work to produce entries in national (or international) competitions such as the Annual CanSat Competition, and the ARLISS Competition. These hands-on activities will be augmented with the fundamentals of autonomous and teleoperated systems and satellite systems design. These will be covered with CubeSat-oriented exercises to round-out the curriculum. 


\section{Evaluation}

The evaluation of the NevadaSat activities has taken the form of informal feedback from students and formal assessment of desired project outcomes. Qualitatively, the feedback received from students who have participated in NevadaSat strongly indicates that student satellites have proved to be a very effective medium for providing both undergraduate and graduate students with "real" multidisciplinary engineering project experience. The attitude of most students can be summed up with the following quote:

"I've realized that my classes haven't taught me much about real engineering."

More formally, the desired outcomes of the NevadaSat project were evaluated in the context of the stated goals of the effort. These included the following:

\begin{tabular}{|c|c|c|}
\hline & Desired Outcome & Measured Outcome \\
\hline 1 & $\begin{array}{l}\text { The students will be able to demonstrate an } \\
\text { understanding of aerospace engineering } \\
\text { project lifecycle and system management } \\
\text { approaches (including teamwork). }\end{array}$ & $\begin{array}{l}\text { Students volunteered for and were assigned project } \\
\text { assignments. Students acquired numerous new skills, } \\
\text { varying from individual to individual. } \\
\text { In the second year, students (generally) played a more } \\
\text { significant role in making their own "big picture" decisions. }\end{array}$ \\
\hline 2 & $\begin{array}{l}\text { Provide students with an understanding of } \\
\text { satellites and balloon systems. }\end{array}$ & $\begin{array}{l}\text { Students received broad exposure to all aspects of the } \\
\text { program through regular group meetings attended by } \\
\text { everyone (BalloonSats, CanSats, CubeSats). Nearly all } \\
\text { systems and subsystems created by the students functioned } \\
\text { properly Students regularly shared their knowledge with } \\
\text { other students to increase team efficiency and flexibility. }\end{array}$ \\
\hline 3 & $\begin{array}{l}\text { Provide students with a project-based } \\
\text { learning environment. }\end{array}$ & $\begin{array}{l}\text { The students participated in various hands-on projects, } \\
\text { acquiring numerous new skills necessary for project success. } \\
\text { Delegation and specialization was critical. Each project area } \\
\text { had a primary and secondary person responsible for it. } \\
\text { Students did develop more advanced experience in their } \\
\text { project areas, making each an integral member of the team. }\end{array}$ \\
\hline 4 & $\begin{array}{l}\text { To provide students with experience } \\
\text { working on interdisciplinary teams. }\end{array}$ & $\begin{array}{l}\text { Students from numerous disciplines worked together on } \\
\text { projects. These included Mechanical, Electrical, Computer, } \\
\text { and Materials Engineering. }\end{array}$ \\
\hline 5 & $\begin{array}{l}\text { Students should participate in the design, } \\
\text { fabrication, operation, and evaluation of } \\
\text { their overall effort. }\end{array}$ & $\begin{array}{l}\text { Students were very hands-on and learned many skills not } \\
\text { normally associated with their "home" disciplines. The team } \\
\text { performed individual and group assessments of performance. }\end{array}$ \\
\hline 6 & $\begin{array}{l}\text { The student researcher(s) will obtain } \\
\text { experience in communicating the results of } \\
\text { their design efforts. }\end{array}$ & $\begin{array}{l}\text { Students prepared a poster and made a technical presentation } \\
\text { at the ARLISS competition. Students assisted in preparing a } \\
\text { paper to be submitted for presentation at the } 2005 \text { ASEE } \\
\text { conference. One graduate student defended a thesis on the } \\
\text { subject of BalloonSat. }\end{array}$ \\
\hline 7 & $\begin{array}{l}\text { The CanSat program will formulate a plan } \\
\text { (in coordination with other NV participants) } \\
\text { addressing how the CanSat activities (and } \\
\text { course) can be extended towards a CubeSat } \\
\text { program. }\end{array}$ & $\begin{array}{l}\text { The investigator team has met with representatives from } \\
\text { other universities and formulated a plan for getting started. } \\
\text { We have begun implementing this advice with the start of } \\
\text { our ground station setup. }\end{array}$ \\
\hline
\end{tabular}




\section{Conclusions}

Many institutions have developed successful student satellite programs. This paper has described the Nevada Space Grant Consortium's experience in starting a student satellite program. The program was largely modeled on existing programs at other Space Grant Consortia. However, even when building upon the experience of others, starting a student satellite program has proved a difficult undertaking.

Nonetheless, from both the students' and institution's point of view, the outcomes are worth the effort. In addition to meeting the aerospace industries workforce development needs, a student satellite program provides students with an opportunity to complete "real" engineering projects while working on multidisciplinary teams.

\section{References Cited}

1. http://ssp.arizona.edu/sgsatellites, accessed: January 3, 2005.

2. Wallace, C. 2004, "High Altitude Balloons: Providing a Cost Effective Testbed for CubeSats," $18^{\text {th }}$ Annual AIAA/USU Conference on Small Satellites, Logan, UT, Aug 8, 2004.

3. Blamont, J., 2001, "History and perspectives of scientific ballooning," Proceedings of the 15th ESA Symposium on European Rocket and Balloon programmes and Related Research, Biarritz, France, ESA SP-471, 28-31 may 2001, Warmbein, B. (ed.), ESA, 71-82.

4. Cathey, H.M. Jr., 2000, “Development of the NASA Long Duration Balloon Vehicle," Advances in Space Research, 26(9):1345-1348.

5. Jones, W. V, 2004, “Global balloon flight obstacles and opportunities," Advances in Space Research, 33(10):1600-1607.

6. Matsuzaka, Y., Yamagami, T., Namiki, M., Toriumi, M., Ohta, S., Makino, F., and H. Hirosawa, 2000, "Thin-film balloon for high altitude observation," Advances in Space Research, 26(9):1365-1368.

7. Needleman, H.C., 1996, “The NASA balloon program: Conventional and long duration," Advances in Space Research, 17(9):29-35.

8. Rainwater, E.L. and M. S. Smith, 2004, "Ultra high altitude balloons for medium-to-large payloads," Advances in Space Research, 33(10):1648-1652.

9. Seely, L.G. and M.S. Smith, 2002, "A realistic view of the future of scientific ballooning," Advances in Space Research, 30(5):1125-1133.

10. Smith, I.S. Jr., 1996, “Advancements in NASA balloon research and development" Advances in Space Research, 17(9):37

11. Smith, I.S. Jr., 2000, "Ultra long duration balloon project," Advances in Space Research, 26(9):1339-1343.

12. Smith, I.S. Jr., 2004, "The NASA Balloon Program: Looking to the future," Advances in Space Research, 33(10):1588-1593.

13. Smith, I.S. Jr.,, 2002, “The NASA Balloon Program: An overview,” Advances in Space Research, 30(5):1087-1094. 
14. https://spacegrant.colorado.edu/studentsat, accessed January 3, 2005.

15. http://www.arliss.org, accessed January 3, 2005.

16. http://www.cansatcompetition.com, accessed January 3, 2005.

17. Matunaga, S., Yoshihara, K., Sugiura, Y., Sekiguchi, M., Sawada, H., Tsurumi, S., Nakaya, K., Mori, M., Ui, K., Maeda, N. and O. Mori, 2000, "Titech micro-satellite model: CanSat for sub-orbital flight," 2000 IEEE Aerospace Conference Proceedings, 7:135-142, Big Sky, MT, March 18-25, 2000.

18. Mutanaga, S., Sawada, H., Furuya, H. and N. Kogiso, 2003 "Lessons learned from small space systems development using magnesium alloys," Materials Science Forum, 419-422:219-224.

19. Gaylash, I., Puig-Suari, J., Moore, A. S., Nakasuka, S., and R. J. Twiggs, 2000b, "CubeSat: A new Generation of Picosatellite for Education and Industry Low-Cost Space Experimentation," Proceedings of the 14th Annual/USU Conference on Small Satellites, Logan, UT, SSC00-III-7, Aug 2000.

20. Gaylsh, I., McGuire, J., Doherty, K., Heidt, H., and D. Niemi, 2000a, "CubeSat: Developing a standard bus for picosatellites," Proceedings of the 45th Annual SPIE Symposium, July 30 - Aug 4, 2000.

21. Kitts, C., Twiggs, R., Pranajaya, F., Palmintier, B., and J. How, 1999, "Emerald: A low-cost spacecraft mission for validating formation flying technologies," 1999 IEEE Aerospace Conference. Proceedings, 2:217-226, Snowmass, CO, March 6-13, 1999.

22. Mathur, R., Haupt, R. and C. Swenson, 2001, "Student antenna design for a nanosatellite," 2001 IEEE Aerospace Conference Proceedings, 7:3688, Big Sky, MT, March, 10-17, 2001.

23. Nason, I., Puig-Suari, J., Twiggs, R., 2002 "Development of a family of picosatellite deployers based on the CubeSat standard," 2002 IEEE Aerospace Conference Proceedings, 1:457-464, Big Sky, MT, March, 9-16, 2002

24. Puig-Suari, J., Turner, C., and W. Ahlgren, 2001, "Development of the standard CubeSat deployer and a CubeSat class picosatellite," 2001 IEEE Aerospace Conference Proceedings, 1:347-353, Big Sky, MT, March, 10-17, 2001.

25. Rausch, W. D., Hartshorn, L. E., Rendon, A., and A. Kitrell, 2000, "CUBESAT - a dual mission picosatellite," Proceedings of SPIE - The International Society for Optical Engineering, 4136:121-130, San Diego, CA, August 3-4, 2000.

26. Schilling, K. and R. Fullmer, 2002, "Control approaches to small student build satellites," Proceedings of the 5th ESA International Conference on Spacecraft Guidance, Navigation and Control Systems, 483, Rome, Italy, October 22-25, 2002.

27. Sellers, J., Sauter, L., Underwood, C. and J. Ward, 2002, "Bounding the problem: microsatellite design using commercial-off-the-shelf architecture," 2002 IEEE Aerospace Conference Proceedings, 5:2399, Big Sky, MT, March, 9-16, 2002.

28. Shiroma, W. A., Ohta, A. T., and M. A. Tamamoto, 2003, "The University of Hawaii CubeSat: A multidisciplinary undergraduate engineering project," Proceedings -Frontiers in Education Conference, S3A7-S3A11, Boulder, CO, November 5-8, 2003.

29. Twiggs, R., 2000 "Space system developments at Stanford University - from launch experience of microsatellites to the proposed future use of picosatellites," Proceedings of SPIE - The International Society for Optical Engineering, 4136:79-86, San Diego, CA, August 3-4, 2000. 
30. Twiggs, R., 2002, "The next generation of innovative space engineers." Proceedings of the 5th ESA International Conference on Spacecraft Guidance, Navigation and Control Systems, 409, Rome, Italy, October 22-25, 2002.

31. Detweiler, J., 2004, "Development of High Altitude Ballooning Hardware," MS Thesis, Department of Mechanical Engineering, University of Nevada, Reno.

\section{Biographical Information}

ERIC L. WANG is an Associate Professor of Mechanical Engineering at the University of Nevada, Reno. Dr. Wang has won numerous awards including the Tibbitts Distinguished Teaching Award, UNR's most prestigious teaching award. In addition to his pedagogical activities, Dr. Wang conducts research on sports equipment, biomechanics, robotics, and intelligent materials.

JEFFREY C. LACOMBE is an Assistant Professor of Metallurgical and Materials Engineering at the University of Nevada, Reno. In addition to his education-oriented research activities, Dr. LaCombe's research lies in the areas of kinetic processes in materials (such as diffusion and solidification), nanoscale manufacturing methods, and remotely operated aerospace \& satellite systems.

JAMES DETWEILER is a Mechanical Engineer at Truckee Precision in Reno, NV. He received both his B.S. and M.S. degrees from the Department of Mechanical Engineering at the University of Nevada, Reno. His M.S. theis dealt with the development of a high altitude ballooning hardware and outreach program.

DANIEL LORANZ earned his doctorate in Cosmology at Montana State University at Bozeman, MT. He has been teaching Physics and Astronomy courses at Truckee Meadows Community College in Reno since the Fall of 1999 and has twice been nominated by the student body for Teacher of the Year. He also attended the workshop Starting Student Space Hardware Programs in June 2002 and the follow-up workshop in June 2003. 